\title{
Use of ESWT in avascular necrosis of bilateral femoral heads: case report
}

\author{
Levent Ozgonenel ${ }^{1}$, Hilal Yesil' ${ }^{2}$, Murat Yesil ${ }^{3}$ \\ ${ }^{1}$ Department of Physical Medicine and Rehabilitation, Medical Park Bahcelievler, Istanbul, Turkey; \\ 2Department of Physical Medicine and Rehabilitation, Usak State Hospital, Usak, Turkey; \\ ${ }^{3}$ Department of Orthopedics and Traumatology, Banaz Public Hospital, Usak, Turkey
}

\begin{abstract}
A 57-year-old female patient was admitted to the department of physical medicine and rehabilitation with lumbar and left hip pain lasting for 1.5 months. Physical examination and magnetic resonance imaging revealed stage 1 avascular necrosis of bilateral femoral heads. Extracorporeal Shock Wave Therapy (ESWT) was utilized for early stage disease and a significant reduction in pain and functional recovery was noted.
\end{abstract}

Key words: Avascular necrosis; conservative; extracorporeal shockwave; femoral head.

\begin{abstract}
$A$ vascular necrosis (AVN) of the femoral head is a progressive disease with sequalae which can cause complete destruction of the femoral head, and requires surgery a few years after its onset [1]. The etiopathogenesis of the avascular necrosis of the femoral head involves histological death of the osteocytes because of insufficient supply of blood flow [2]. Based on our current information about AVN of the femoral head, increased intraosseous pressure developed following an ischemic attack in addition to enhanced edema in functionally constrained region of the bone marrow compartment creates a vicious cycle just like a compartment syndrome which compresses venules, and arterioles [3]. Essentially, diagnosis of AVN of the femoral head is made based on radiograms obtained at antero-
\end{abstract}

posterior, lateral, and frog leg positions. However, in the early stage AVN of the femoral head these radiograms have lower diagnostic sensitivity. Magnetic resonance imaging (MRI) has a 99\% diagnostic sensitivity, and $98 \%$ specificity even in the early stage of AVN of the femoral head [4]. International classification system proposed by Association Research Circulation Osseous (ARCO) in 1993 also includes previous classifications [5,6].

Though current treatments in the management of AVN of the femoral head are still debatable, in cases of failed conservative treatment, as surgical methods, osteotomy, vascularized or non-vascularized bone grafting, and femoral head preservation surgery as core decompression are used, while in advanced stages (especially ARCO III, and IV) total 
TABLE 1. Indications, and Containdications according to the Guidelines of International Society of Musculoskeletal Shock Wave Treatment (ISMST)

\begin{tabular}{ll} 
Indications & Contraindications \\
\hline Pseudoarthrosis/nonunion & Soft tissue / acute infections of the bone \\
Tendinosis of the shoulder joint & Malignancy \\
Chronic radial epicondylitis & Coagulopathies \\
Plantar fasciitis ( \pm heel spur) & Pregnancy \\
& Previously implanted pacemaker \\
& Epiphysiolysis at the site of application \\
& Lung tissue at the site of application \\
& Presence of cerebral, spinal cord tissue or \\
& major vessels at the site of application
\end{tabular}

hip prosthesis is preferred [7]. Conservative treatments include prostacycline analogues, enoxaparine, and alendronate therapies. The most frequently used treatment agents include pulsed electromagnetic field (PEMF), and extracorporeal shock wave therapies (ESWT) Essentially ESWT is thought to activate cellular processes critical for neurovascularization, and tissue regeneration [7-10]. Ma et al. concluded that therapeutic effects of ESWT might be associated with vascular endothelial growth factor (VEGF). VEGF has a mitogenic effect on vascular endothelial cells, and stimulates neovascularization. Still another study performed by $\mathrm{Ma}$ et al. in the year 2008, detected that expression of BMP2 (bone morphogenic protein) increased on femoral heads of the patients treated with ESWT. BMP-2 mobilizes osteoprogenitor (precursor) cells inducing osteoblastic differentiation process leading to stimulation of new bone formation [9]. Other current studies have also emphasized favourable effects of ESWT in the management of AVN of the femoral head $[10,11,12]$. In summary, ESWT exerts its effectiveness in the management of avascular necrosis of femoral head through neovascularization, and regeneration of the bone.

\section{CASE REPORT}

A 57-year-old female patient was admitted to the department of physical medicine and rehabilitation with lumbar and left hip pain present for 1.5 months. Patient indicated that she hadn't any pain at night, and her pains aggravated with movement. Physical examination revealed restricted internal rotation, tense left tensor fascia lata band $(+)$ Fabere Fader, and Laseque test negativity. Magnetic resonance imaging demonstrated subchondral edematous ring on both femoral heads, and interpreted as stage I AVN of the femoral head. For preprocedural indication, containdications, and application methods, ESWT protocol published by International Society for Musculoskeletal Shock Wave Therapy was taken into consideration (Table 1). Under regional anesthesia, the patient was transferred on operation table in supine position. For maximum visualization of the femoral head the affected hip was brought into " frog leg " position. Priorly the place of the femoral artery was determined by ultrasonography, and marked with a pencil. Then $\mathrm{k}$-wire was placed on the course of the femoral artery so as to facilitate its visualization under scopy. The site of the necrotic changes on the femoral head where therapy will be applied was determined with the aid of fluoroscopy, and marked on the headpiece with 4 dots. Then k-wire was removed, then using a $\mathrm{Zim}$ mer ${ }^{\oplus}$ brand ESWT device, from a site far away from the artery, 3 times 2000 impacts at 0.11 to $0,28 \mathrm{~mJ} /$ $\mathrm{mm}^{2}$ were applied. Before, and after the procedure, hip muscles demonstrated full muscular strength. Before the procedure the patient complained of pain when she ascended two stairs, while after the procedure she climbed 4 stairs, and walked for 30 
minutes without pain. Evaluation with Visual Analogue Scale (VAS) demonstrated marked alleviation in her hip pain, and 15 days after she didn't use her walking stick any more.

\section{DISCUSSION}

The functional state of the hips affected by AVN of the femoral head tends to worsen because of progressive collapse of the femoral head. Most frequently AVN causes articular destruction which consequently leads to requirement for hip arthroplasty. In a study performed by Ohzono et al., the authors reported that the lesions were localized on the weightbearing areas of the femoral head, and incidence of collapsed femoral head within 5 years ranged between 94, and 100 percent [13]. Even though AVN treatment was debatable, generally, surgery is used in cases with failed conservative treatment. Nonsurgical treatment alternatives in the management of early stage AVN include controlled weight-loading, ESWT, and PEMF. Though complete mechanism of activity of the ESWT is not already known, in various studies performed, it has been associated with increases in the levels of BMP-2, and VEGF. Increases in both of these markers stimulate neovascularization together with new bone formation $[9,14]$. In a recent study performed by Hausdorf et al., the authors reported that ESWT penetrates into targeted femoral head in proportion with the distance between the ESW device, and the femoral head. The authors also indicated that despite $10 \mathrm{~mm}$ safe bone margin, ESWT achieves a $50 \%$ decrease in the therapeutic effect, and they also asserted that adequate clinical evidence was available suggesting the presence of a biological response characterized by increased bone formation by means of neovascularization process [15]. Besides, ESWT plays an important role in the alleviation of hip pain, recovery of functions, and increase in the quality of life of the patient especially in the management of early stage femoral head AVN (ARCO stage I, and II) $[7,10,11,12]$. In a study by Wang et al., the authors reported that ESWT was more effective than core-decompression, and non-vascularized fibula grafting [12]. In a study conducted in 2008 in the treatment of AVN of the femoral head synergistic therapeutic effects of ESWT, and alendronate were reported [10]. Finally, Wang et al. evaluated effec- tiveness of ESWT in the management of AVN of the femoral head in a long-term (8-9 years) followup study, and reported that in the early stage AVN, ESWT was more significantly effective than surgical alternatives including core decompression, and non-vascularized fibula grefting [16].

In conclusion, substantial amount of information in the current medical literature advocates effectiveness of ESWT especially in the early stage of AVN of the femoral head. Also we have obtained improved treatment outcomes in the early stage (Stage 1) AVN of the femoral head, and pain, and functional restriction of the patient resolved markedly.

Conflict of Interest: No conflict of interest was declared by the authors.

Financial Disclosure: The authors declared that this study has received no financial support.

\section{REFERENCES}

1. Lee MS, Hsieh PH, Shih CH, Wang CJ. Non-traumatic osteonecrosis of the femoral head - from clinical to bench. Chang Gung Med J 2010;33:351-60.

2. Chandler FA. Coronary disease of the hip. J Int Coll Surg 1948;11:34-6.

3. Vulpiani MC, Vetrano M, Trischitta D, Scarcello L, Chizzi F, Argento G, et al. Extracorporeal shock wave therapy in early osteonecrosis of the femoral head: prospective clinical study with long-term follow-up. Arch Orthop Trauma Surg 2012;132:499. 508. CrossRef

4. Theodorou DJ, Malizos KN, Beris AE, Theodorou SJ, Souca$\cos$ PN. Multimodal imaging quantitation of the lesion size in osteonecrosis of the femoral head. Clin Orthop Relat Res 2001;386:54-63. CrossRef

5. Gardeniers JWM. The ARCO perspective for reaching one uniform staging system of osteonecrosis. In: Scoutens A, Arlet J, Gardeniers JWM, Hughes SPF, editors. Bone circulation and vascularization in normal and pathologic conditions. New York: Plenum; 1993. p. 375-80. CrossRef

6. Steinberg ME, Hayken GD, Steinberg DR. A quantitative system for staging avascular necrosis. J Bone Joint Surg Br 1995;77:34-41.

7. Wang CJ, Wang FS, Ko JY, Huang HY, Chen CJ, Sun YC, et al. Extracorporeal shockwave therapy shows regeneration in hip necrosis. Rheumatology (Oxford) 2008;47:542-6. CrossRef

8. Hopper RA, VerHalen JP, Tepper O, Mehrara BJ, Detch R, Chang EI, et al. Osteoblasts stimulated with pulsed electromagnetic fields increase HUVEC proliferation via a VEGF-A independent mechanism. Bioelectromagnetics 2009;30:189-97. CrossRef

9. Ma HZ, Zeng BF, Li XL, Chai YM. Temporal and spatial ex- 
pression of BMP-2 in sub-chondral bone of necrotic femoral heads in rabbits by use of extracorporeal shock waves. Acta Orthop 2008;79:98-105. CrossRef

10. Wang CJ, Wang FS, Yang KD, Huang CC, Lee MS, Chan YS, et al. Treatment of osteonecrosis of the hip: comparison of extracorporeal shockwave with shockwave and alendronate. Arch Orthop Trauma Surg 2008;128:901-8. CrossRef

11. Russo S, Corrado EM, Corrado B, Benigno T. The role of extracorporeal shock waves. In: Santori FS, Santori N, Piccinato A, editors. Avascular necrosis of the femoral head: current trends. Milan: Springer; 2004, p. 45-54. CrossRef

12. Wang CJ, Wang FS, Huang CC, Yang KD, Weng LH, Huang HY. Treatment for osteonecrosis of the femoral head: comparison of extracorporeal shock waves with core decompression and bone-grafting. J Bone Joint Surg Am 2005;87:2380-7. CrossRef
13. Ohzono K, Saito M, Sugano N, Takaoka K, Ono K. The fate of nontraumatic avascular necrosis of the femoral head. A radiologic classification to formulate prognosis. Clin Orthop Relat Res 1992;277:73-8.

14. Ma HZ, Zeng BF, Li XL. Upregulation of VEGF in subchondral bone of necrotic femoral heads in rabbits with use of extracorporeal shock waves. Calcif Tissue Int 2007;81:124-31. CrossRef

15. Hausdorf J, Lutz A, Mayer-Wagner S, Birkenmaier C, Jansson V, Maier M. Shock wave therapy for femoral head necrosis-Pressure measurements inside the femoral head. J Biomech 2010;43:2065-9. CrossRef

16. Wang CJ, Huang CC, Wang JW, Wong T, Yang YJ. Long-term results of extracorporeal shockwave therapy and core decompression in osteonecrosis of the femoral head with eight- to nine-year follow-up. Biomed J 2012;35:481-5. 